\title{
Re-experiencing Violence Across the Life Course: Histories of Childhood Maltreatment and Elder Abuse Victimization
}

\author{
Jooyoung Kong, $\mathrm{PhD}^{1}$ and Scott D. Easton, $\mathrm{PhD}^{2}$
}

${ }^{1}$ Center for Healthy Aging, College of Health and Human Development, Pennsylvania State University, University Park. ${ }^{2}$ School of Social Work, Boston College, Chestnut Hill, Massachusetts.

Address correspondence to: Jooyoung Kong, PhD, Center for Healthy Aging, College of Health and Human Development, Pennsylvania State University, 422 Biobehavioral Health Building, University Park, PA 16802. E-mail: jzk255@psu.edu

Received: August 23, 2017; Editorial Decision Date: February 22, 2018

Decision Editor: Deborah Carr, PhD

\begin{abstract}
Objectives: This study primarily examines the associations between histories of childhood maltreatment (i.e., neglect, emotional, physical, and sexual abuse) and elder abuse victimization and explores whether gender moderates the associations. Methods: We conducted a secondary data analysis of 5,968 older adults (mean age $=71$ years) based on data from the Wisconsin Longitudinal Study (2010-2011). Using retrospective self-reports of childhood and current (past 12 months) victimization experiences, logistic regression analyses were conducted to estimate the effects of early-life adversities on the likelihood of elder abuse victimization.

Results: Results indicate that childhood emotional abuse and childhood sexual abuse (CSA) were associated with greater risk of being abused as older adults, after controlling for childhood and adult background factors. We also found that the effect of CSA on elder abuse victimization was weaker for women than men.

Discussion: Findings suggest that the phenomenon of revictimization may occur not only in early and middle adulthood, but also in late life. To advance our understanding of victimization across the life course, future research on root causes of elder abuse should include histories of child abuse.
\end{abstract}

Keywords: Child sexual abuse, Elder mistreatment, Revictimization

Elder abuse has become a recognized, prevalent public health issue. Population-based studies have shown that $5 \%-10 \%$ of older adults in the United States experience a type of mistreatment, including emotional, physical, and sexual abuse and financial exploitation (Burnes et al., 2015; Laumann, Leitsch, \& Waite, 2008). A growing number of empirical studies have identified risk factors for elder abuse, such as older adults' health status, living arrangement, and financial dependency (Johannesen \& LoGiudice, 2013). However, prior investigations have concentrated on proximal factors; effects of early life-course factors, such as childhood victimization, have been virtually unexplored.

Despite little research, empirical and theoretical literature has suggested that victimization reoccurs across the life course.
The cumulative disadvantage hypothesis postulates that earlylife adversity can increase susceptibility to subsequent adverse experiences in adulthood (Dannefer, 1987; O'Rand, 1996; Schafer, Ferraro, \& Mustillo, 2011). The concept of revictimization, an increased likelihood of adult victimization following childhood victimization, is well established and supported by extensive empirical evidence (Classen, Palesh, \& Aggarwal, 2005; Messman \& Long, 1996). For example, Miron and Orcutt (2014) found that histories of childhood physical and sexual abuse were associated with a greater risk of being sexually assaulted among a sample of college women. Few studies, however, have explored this phenomenon among older adults.

This study aims to advance knowledge by expanding the concept of revictimization to include elder abuse. Because 
victimization has been considered a gendered phenomenon, as reflected by a large number of prior studies based on predominantly (or exclusively) female samples (e.g., Roberto, Teaster, \& Duke, 2004), we examined the moderating effect of gender in recurrent victimization experiences in late adulthood. Using data from the large, populationbased Wisconsin Longitudinal Study (WLS), we evaluated the following hypotheses: (a) histories of childhood victimization (i.e., neglect, emotional, physical, sexual abuse) will increase the likelihood of being victimized in late adulthood, and (b) gender will moderate these associations.

\section{Methods}

\section{Data Source}

We relied on secondary data from the WLS, which is a longitudinal, population-based study that first surveyed a random sample of 10,317 high school graduates in 1957. Data were subsequently collected in 1993-1994 (Wave 1), 2004-2005 (Wave 2), and 2010-2011 (Wave 3), which provides extensive information on respondents from late adolescence through the mid-70s. Retention rates have been high among surviving graduates: $74.6 \%$ of graduates participated in at least two of the three waves (WLS, n.d.). This study analyzed data from 5,968 participants at Wave 3 whose average age was 71 years (range: 70-73). In that wave, participants were asked to report current victimization (i.e., past 12 months). A retrospective measure of childhood maltreatment was drawn from Wave 2; at that time, the average age of respondents was 65 years (range: 64-67).

\section{Measures}

\section{Elder abuse victimization}

Elder abuse victimization was assessed by five items that correspond with key items from the Abusive Behavior Inventory (Shepard \& Campbell, 1992): "In the past 12 months, (a) have you felt there is someone who is too controlling over your daily decisions and life?; (b) has anyone insulted you or put you down?; (c) has anyone taken your money or belongings without your permission or prevented you from getting them even when you ask?; (d) has anyone hit, kicked, slapped, or thrown things at you?; (e) has anyone intentionally prevented you from having things you need, such as medication, food, money, or personal care?" Response choices for each item were binary: yes (1) and no (0). Respondents who responded yes to any of these five questions were coded as being victimized $(1 ; n o=0)$.

\section{Childhood neglect}

Childhood neglect was measured by an item: "Up until you were 18 , how often did you know that there was someone to take care of you and protect you?" Response choices were based on a 5-point Likert scale: never (1), rarely (2), sometimes (3), often (4), and very often (5). Responses were reverse coded; higher values indicate more frequent neglect.

\section{Childhood verbal/physical abuse}

These concepts were assessed using adapted items from the Conflict Tactics scale (Straus, Gelles, \& Steinmetz, 1980). Childhood verbal abuse was measured by two items: "Up until you were 18, to what extent did (a) your mother, (b) father insult or swear at you?" Response choices were based on a 4-point Likert scale: not at all (1), a little (2), some (3), and a lot (4). Childhood physical abuse was measured by two items: "Up until you were 18 , to what extent did (a) your mother, (b) father treat you in a way that you would now consider physical abuse?" Response choices were based on a 4-point Likert scale: not at all (1), a little (2), some (3), and a lot (4). Responses were averaged on both variables.

\section{Childhood sexual abuse}

To assess for childhood sexual abuse (CSA), we relied on four items from the WLS: "Up-until 18, to what extent (a) did your father have oral, anal, or vaginal sex with you against your wishes?; (b) did any other person have oral, anal, or vaginal sex with you against your wishes?; (c) did your father treat you in way that you consider sex abuse?; (d) did any other person treat you in way that you consider sex abuse?" Response choices were based on a 4-point Likert scale: not at all (1), a little (2), some (3), and a lot (4). A binary variable was created because of the skewness of data. Respondents who answered a little, some, or a lot for any item were coded as having been sexually abused during childhood $(1 ; n o=0)$.

\section{Control variables}

We included other childhood adversities that often cooccur with childhood maltreatment: witnessing domestic violence, living in a single parent household, and living with a problem drinker or alcoholic. Witnessing domestic violence was assessed with a single item: "Up until you were 18, how often did you see a parent or one of your brothers or sisters get beaten at home." Response choices were based on a 5-point Likert scale ranging from never (1) to very often (5). Responses of sometimes, often, and very often were coded as having witnessed domestic violence ( 1 ; $n o=0$ ). We also included variables regarding whether or not respondents lived in a single parent household, lived with a problem drinker, and grew up in a rural background $(1 ; n o=0)$, as well as father's years of education.

Based on prior studies regarding risk factors for elder abuse (e.g., Johannesen \& LoGiudice, 2013), we included several later-life characteristics as covariates: gender $(0=$ male, $1=$ female $)$, marital status $(0=$ non-married, $1=$ married $)$, self-rated health condition $(0=$ very poor $/$ poor/fair, 1 = good/excellent), respondents' years of education, number of children, and total household income. Gender was also used as a moderator in the analysis. 
Analytic procedures

Using Stata 14, logistic regression analyses were conducted to estimate the association between early-life adverse experiences and elder abuse victimization. In Model 1, childhood maltreatment predictors (i.e., neglect, emotional, physical, and sexual abuse) and control variables were entered. Model 2 included interaction terms between four childhood maltreatment measures and gender. Complete data were provided by $71 \%$ of respondents. Multiple imputations by chained equations were used to address missingness and generated 20 imputed data sets.

\section{Results}

Table 1 presents sample characteristics and frequencies of key variables. More than $15 \%$ of respondents $(n=975)$ experienced elder abuse. Approximately, half of respondents were women $(n=3,191)$; most respondents were married $(72.3 \%)$ and reported good to excellent health $(71.2 \%)$. On average, respondents completed 13.8 years of education. One third of respondents $(n=1,800)$ reported that they lived in rural areas during childhood.

Table 2 summarizes the results of logistic regression models. In Model 1, more frequent exposure to childhood emotional abuse was associated with a greater risk of elder abuse victimization (odds ratio, $\mathrm{OR}=1.37, p<.001$ ), after controlling for childhood and adult characteristics. A history of CSA was another significant predictor; the odds of elder abuse victimization were about two times higher for adults with a history of CSA compared with those with no reported history of CSA (OR $=1.95, p<.001)$. Also, the odds of elder abuse victimization were 1.5 times higher for women than for men $(\mathrm{OR}=1.50, p<.001)$. Model 2 included interaction terms between histories of childhood maltreatment and gender. We found a significant moderating effect of gender on the association between CSA and elder abuse victimization $(\mathrm{OR}=0.49, p<.05)$. For men, the odds of being victimized as older adults were 3.3 times higher for adults with a history of CSA compared with those with no history of CSA (OR $=3.34, p<.001)$; for women, the odds of being victimized as older adults were 1.6 times higher for adults with CSA compared with those with no reported history of CSA $(3.34 \times 0.49=1.64)$.

\section{Discussion}

The primary purposes of this study were to examine links between histories of childhood maltreatment and later-life victimization and to evaluate the moderating effect of gender in these associations. We found empirical evidence that childhood emotional and sexual abuse were associated with greater risks of elder abuse victimization. This result is consistent with McDonald and Thomas (2013) who found that a history of childhood abuse heightened the risk of being abused as an older adult. In addition, this study extends prior studies on recurring sexual victimizations (e.g., Miron \& Orcutt, 2014),

Table 1. Study Sample Characteristics $(N=5,968)$

\begin{tabular}{|c|c|c|c|}
\hline & $N(\%)$ & Mean $(S D)$ & Min./Max. \\
\hline Elder abuse victimization (the past 12 months) & $975(16.34)$ & & $0 / 1$ \\
\hline Felt someone too controlling over your daily decisions and life & $394(6.60)$ & & \\
\hline Had anyone insulted you or put you down & $742(12.43)$ & & \\
\hline $\begin{array}{l}\text { Had anyone taken your money or belongings without your permission or } \\
\text { prevented you from getting them }\end{array}$ & $94(1.58)$ & & \\
\hline Had anyone hit, kicked, slapped, or thrown things at you & $28(0.47)$ & & \\
\hline $\begin{array}{l}\text { Had anyone intentionally prevented you from having things you need (e.g., } \\
\text { food) }\end{array}$ & $18(0.30)$ & & \\
\hline Childhood neglect & & $1.52(0.91)$ & $1 / 5$ \\
\hline Childhood emotional abuse & & $1.30(0.53)$ & $1 / 4$ \\
\hline Childhood physical abuse & & $1.17(0.47)$ & $1 / 4$ \\
\hline Childhood sexual abuse & $313(5.24)$ & & $0 / 1$ \\
\hline Other childhood adversities & & $.34(0.60)$ & $0 / 3$ \\
\hline Years of father's education & & $9.84(3.46)$ & $0 / 25$ \\
\hline Rural background & $1,800(30.16)$ & & $0 / 1$ \\
\hline \multicolumn{4}{|l|}{ Gender } \\
\hline Male & $2,777(46.53)$ & & $0 / 1$ \\
\hline Female & $3,191(53.47)$ & & $0 / 1$ \\
\hline Married & $4,312(72.25)$ & & $0 / 1$ \\
\hline Years of education & & $13.77(2.35)$ & $5 / 20$ \\
\hline Household income $(\$)$ & & $48,784.18(66,679.74)$ & $0 / 600,000$ \\
\hline Good or excellent health & $4,246(71.15)$ & & $0 / 1$ \\
\hline Number of children & & $3.19(1.78)$ & $0 / 10$ \\
\hline
\end{tabular}

Note. Values are reported prior to data transformation and multiple imputation. 
Table 2. Logistic Regression Predicting Elder Abuse Victimization

\begin{tabular}{|c|c|c|}
\hline & Model 1 & Model 2 \\
\hline & OR $(95 \% \mathrm{CI})$ & OR $(95 \% \mathrm{CI})$ \\
\hline Childhood neglect & $1.00(0.92,1.10)$ & $0.95(0.83,1.08)$ \\
\hline Childhood emotional abuse & $1.37(1.15,1.62)^{* * *}$ & $1.37(1.06,1.77)^{*}$ \\
\hline Childhood physical abuse & $1.18(0.96,1.44)$ & $1.20(0.88,1.62)$ \\
\hline Childhood sexual abuse & $1.95(1.48,2.55)^{* * * *}$ & $3.34(1.88,5.94) * *$ \\
\hline Childhood neglect $\times$ female & & $1.12(0.94,1.33)$ \\
\hline Childhood emotional abuse $\times$ female & & $0.99(0.71,1.39)$ \\
\hline Childhood physical abuse $\times$ female & & $0.96(0.68,1.37)$ \\
\hline Childhood sexual abuse $\times$ female & & $0.49(0.26,0.92)^{*}$ \\
\hline Witnessed domestic violence & $1.20(0.90,1.62)$ & $1.20(0.89,1.62)$ \\
\hline Lived in a single parent household & $0.86(0.67,1.12)$ & $0.87(0.67,1.12)$ \\
\hline Lived with a problem drinker & $1.16(0.95,1.41)$ & $1.16(0.95,1.42)$ \\
\hline Female & $1.50(1.28,1.75) * * *$ & $1.56(1.33,1.83) * * *$ \\
\hline Married & $1.17(0.99,1.38)$ & $1.17(0.99,1.38)$ \\
\hline Years of education & $1.08(1.04,1.11) * * *$ & $1.08(1.04,1.11)^{* * *}$ \\
\hline Years of father's education & $1.01(0.98,1.03)$ & $1.01(0.98,1.03)$ \\
\hline Household income $(\$)$ & $1.00(1.00,1.00)$ & $1.00(1.00,1.00)$ \\
\hline Good or excellent health & $0.63(0.52,0.76)^{* * * *}$ & $0.63(0.52,0.76) * *$ \\
\hline Rural background & $0.91(0.78,1.07)$ & $0.92(0.78,1.08)$ \\
\hline Number of children & $1.03(0.99,1.08)$ & $1.03(0.99,1.08)$ \\
\hline Constant & $0.07(0.04,0.12) * * *$ & $0.07(0.04,0.12)^{* * * *}$ \\
\hline
\end{tabular}

Notes. The analyses were conducted using imputed data. Odds ratios with confidence intervals in parentheses.

Significance levels are denoted as $* p<.05, * p<.01, * * p<.001$.

as we found that a history of CSA increased older adults' susceptibility to other forms of abuse (i.e., non-sexual violence) later in adulthood. As postulated by the cumulative disadvantage hypothesis, childhood victimization may make the child survivors more vulnerable to later-life mistreatment. To disentangle persistent toxic effects of childhood adversities in later life, future research should identify mechanisms that potentially sustain subsequent victimization. For example, long-term correlates of childhood maltreatment, such as social isolation, maladaptive coping, or psychological dysfunctions (Briere \& Jordan, 2009), may explain why victimization experiences can recur across the life course.

Another important finding is related to the gender difference in the effect of CSA on elder abuse victimization. For both men and women, CSA was associated with a greater likelihood of being victimized as older adults, but interestingly, the risk appears to be higher for men. This result may be explained by emerging research on male survivors of CSA. For example, Easton and colleagues found that boys/men are often marginalized after sexual victimization, are at risk for mental health challenges across the life course, and face numerous individual and systematic barriers to disclosure and help-seeking (Easton \& Kong, 2017; Easton, Kong, Gregas, Shen, \& Shafer, in press). Because of factors such as stigma, self-blame, and fears related to compromised masculinity, male survivors of CSA tend to delay disclosing childhood victimization, which can further complicate psychological distress and prevent them from accessing intervention services (Easton, 2013; 2014).
Furthermore, support services tailored to address unique concerns and challenges of male survivors of CSA are currently lacking (Easton, Saltzman, \& Willis, 2014). Future research should explore how the specific gendered experience of CSA and its impact on revictimization unfolds across the life course.

Our study has limitations related to the use of secondary data. First, retrospective self-reports of childhood and elder victimization may involve recall errors and underreporting issues. Particularly, the elder abuse measure evaluated a limited scope of abuse types and lacked the ability to assess regularity, severity, and chronicity of the victimization experience. Psychological distress and interpersonal impairments resulting from childhood trauma may also make older adults more likely to perceive their current situation or relationship as abusive (Briere \& Jordan, 2009). Additionally, the WLS is largely representative of older White American high school graduates; results may not be generalizable to all segments of the U.S. population, especially racial and ethnic minorities (Herd, Carr, \& Roan, 2014).

Despite these limitations, this study advances the elder abuse literature by identifying histories of childhood maltreatment as key predictors of elder victimization. It also highlights the importance of integrating two separate life stages (i.e., childhood and late adulthood) to better understand the phenomenon of revictimization. For practitioners working with older people who are currently victimized, it will be important to understand the clients' current environment based on early childhood histories and help 
address unresolved emotional and relational issues from past traumatic experiences.

\section{Author Contributions}

J. Kong planned the study, performed all statistical analyses, and wrote the paper. S. D. Easton developed the key research question, reviewed statistical analyses, and assisted in writing and revising the paper.

\section{Funding}

This study was supported by the National Institute on Aging Grants T32 AG049676 to The Pennsylvania State University and R03 AG048768 to Scott D. Easton, PhD.

\section{Conflict of Interest}

None reported.

\section{References}

Briere, J., \& Jordan, C. E. (2009). Childhood maltreatment, intervening variables, and adult psychological difficulties in women: An overview. Trauma, Violence \& Abuse, 10, 375-388. doi:10.1177/1524838009339757

Burnes, D., Pillemer, K., Caccamise, P. L., Mason, A., Henderson, C. R. Jr, Berman, J.,...Lachs, M. S. (2015). Prevalence of and risk factors for elder abuse and neglect in the community: A population-based study. Journal of the American Geriatrics Society, 63 , 1906-1912. doi:10.1111/jgs.13601

Classen, C. C., Palesh, O. G., \& Aggarwal, R. (2005). Sexual revictimization: A review of the empirical literature. Trauma, Violence \& Abuse, 6, 103-129. doi:10.1177/1524838005275087

Dannefer, D. (1987). Aging as intracohort differentiation: Accentuation, the Matthew Effect, and the life course. Sociological Forum, 2, 211-236.

Easton, S. D. (2013). Disclosure of child sexual abuse among adult male survivors. Clinical Social Work Journal, 41, 344-355. doi:10.1007/s10615-012-0420-3

Easton, S. D. (2014). Masculine norms, disclosure, and childhood adversities predict long-term mental distress among men with histories of child sexual abuse. Child Abuse \& Neglect, 38, 243251. doi:10.1016/j.chiabu.2013.08.020

Easton, S. D., \& Kong, J. (2017). Mental health indicators fifty years later: A population-based study of men with histories of child sexual abuse. Child Abuse and Neglect, 63, 273-283. doi:10.1016/j.chiabu.2016.09.011
Easton, S. D., Kong, J., Gregas, M., Shen, C., \& Shafer, K. (in press). Child sexual abuse and depression in late life for men: A population-based longitudinal analysis. The Journals of Gerontology Series B: Psychological Sciences and Social Sciences. Online first: doi:10.1093/geronb/gbx114

Easton, S. D., Saltzman, L., \& Willis, D. (2014). "Would you tell under circumstances like that?": Barriers to disclosure for men who were sexually abused during childhood. Psychology of Men and Masculinity, 15, 460-469. doi:10.1037/a0034223

Herd, P., Carr, D., \& Roan, C. (2014). Cohort profile: Wisconsin longitudinal study (WLS). International Journal of Epidemiology, 43, 34-41. doi:10.1093/ije/dys194

Johannesen, M., \& LoGiudice, D. (2013). Elder abuse: A systematic review of risk factors in community-dwelling elders. Age and Ageing, 42, 292-298. doi:10.1093/ageing/afs195

Laumann, E. O., Leitsch, S. A., \& Waite, L. J. (2008). Elder mistreatment in the United States: Prevalence estimates from a Nationally Representative Study. The Journals of Gerontology: Psychological Sciences and Social Sciences, 68, S248-S254. doi:10.1093/geronb/63.4.S248

McDonald, L., \& Thomas, C. (2013). Elder abuse through a life course lens. International Psychogeriatrics, 25, 1235-1243. doi:10.1017/S104161021300015X

Messman, T. L., \& Long, P. J. (1996). Child sexual abuse and its relationship to revictimization in adult women: A review. Clinical Psychology Review, 16, 397-420.

Miron, L. R., \& Orcutt, H. K. (2014). Pathways from childhood abuse to prospective revictimization: Depression, sex to reduce negative affect, and forecasted sexual behavior. Child Abuse and Neglect, 38, 1848-1859. doi:10.1016/j.chiabu.2014.10.004

O'Rand, A. M. (1996). The precious and the precocious: Understanding cumulative disadvantage and cumulative advantage over the life course. The Gerontologist, 36, 230-238.

Roberto, K. A., Teaster, P. B., \& Duke, J. O. (2004). Older women who experience mistreatment: Circumstances and outcomes. Journal of Women \& Aging, 16, 3-16. doi:10.1300/J074v16n01_02

Schafer, M. H., Ferraro, K. F., \& Mustillo, S. A. (2011). Children of misfortune: Early adversity and cumulative inequality in perceived life trajectories. AJS; American Journal of Sociology, 116, 1053-1091. doi:10.1086/655760

Shepard, M. F., \& Campbell, J. A. (1992). The abusive behavior inventory: A measure of psychological and physical abuse. Journal of Interpersonal Violence, 7, 291-305.

Straus, M. A., Gelles, R. J., \& Steinmetz, S. K. (1980). Behind closed doors: Violence in the American family. New York, NY: Anchor Books.

Wisconsin Longitudinal Study (WLS). (n.d.). Retention and response rates. Retrieved from http://www.ssc.wisc.edu/wlsresearch/documentation/retention/cor1004_retention.pdf 